

\title{
The Effect of Using Active Learning on the Performance Level of High Passing Technique in Volleyball for the Pupils of the Second Level of Basic Education
}

\author{
Walid Zaghloul Hamed Atiyah ${ }^{1}$ \\ ${ }^{1}$ Lecturer, Faculty of Physical Education for Boys, Zagazig University, Egypt
}

\begin{abstract}
Learning is considered one of the most important aspects and attributes, that plays an important role in the progress of many peoples, as it has a positive and comprehensive influence in upbringing a new generation by modern and promoted scientific basics. The success of the educational process depends mainly on teaching and learning methods. Many calls have been launched in recent years recommends to follow the methods that stimulate and encourage the student to be more positive and interactive with what he/she learns. Active learning is a response to those variables that require reconsideration of the roles of both the learner and the teacher, which called for transferring the attention from the teacher to the learner and even making the learner the main axis in the educational process. The researcher used the active learning (exchange learning and collaborative learning strategies) to teach the high pass in volleyball to stimulate the learners to participate actively in learning and teaching processes themselves the two active learning strategies, which help raising the level of their performance of the high passing skill as the active learning is a modern method of teaching, which encourages the learner to actively participate in the educational process.
\end{abstract}

\section{Introduction and Importance of the Study}

$\mathrm{L}$ earning is considered one of the most important aspects and attributes, that plays an important role in the progress of many peoples, as it has a positive and comprehensive influence in upbringing a new generation by modern and promoted scientific basics, The achieved progress is measured by the extent of knowledge of the ways, means and theories of teaching and modern teaching methods, scientific development added many new ways which can be useful for the teacher in preparing areas of expertise to the teacher/students until they are prepared with a high degree of efficiency, and that the task of the teacher is no longer limited to the explanation and narrating and following the traditional methods of teaching, but his/her primary responsibility is to plan for strategies for the lesson in which the teaching methods and teaching aids work on achieving specific goals. (6:36)

Ameen El-Khouly and Gamal-Eldeen El-Shaf'ey (2000), and Mohamed El-Hamamy and Ameen El-Khouly (1990) point that Physical Education as en educational activity has its effect on the individual's physical, skillful, cognitive, social and emotional aspects, and it's important to keep pace with scientific and technological development for preparing the teacher and to get him/her trained professionally, so he/she in turn can transfer his/her knowledge and information using the most appropriate ways and methods. (5-119), (13:59)

Makarem Abu-Harjah and Mohamed Saad (1999) have proven that the success of the educational process depends mainly on the used teaching and learning methods, many calls have been launched in recent years recommending to follow the methods that stimulate and encourage the student to be more positive and interactive with what he/she learns, to has the ability to search for knowledge by himself/herself, to has the spirit of inquiry and desire for discovery, and finally to make the teaching and learning process more fun, exciting and interesting. (19:18)

The researcher believes that an efficient teacher is the one who can constantly provide the latest information and has as much introductions of direct and indirect teaching, as he/she who can get the learner used to search and explore through the positive and active participation during the teaching process.

According to Mohammed Hamdan (2006), active learning is a response to those variables that require reconsideration of the roles of both the learner and the teacher, which called for transferring the attention from the teacher to the learner and even making the learner the main axis in the 
educational process, some of its features include what is related to academic aspects and human relations and communication between learners each other. (16:16)

The Active Learning Guide (2006) holds that active learning strategies are efficient in the presence of a general plan set to achieve certain goals and to produce the desired outputs, those outputs are represented in a group of decisions taken by the teacher and are reflected in the types of acts performed by the teacher and the learner in an educational situation, even though there is no specific strategy better than the other but there are some strategies to achieve the desired learning objectives in a teaching position better than others. $(9: 25)$

Also Borhamy Abdel-Hamid agreed with Saada et al. (2012) that active learning is a challenge for the teacher in terms of his ability to choose appropriate activities in that kind of learning, and apply them in the exact time, so the exercise gets its importance in the light of these activities, and the active learning becomes effective. (7:53)

The researcher as a teacher of physical education and a supervisor of practical education to the fourth division students at the Faculty of Physical Education, observed that the pupils tend to participate in the lessons of physical education in football field rather than any other team sports activities, this is due to their passion for this sport as it is the most popular of all sports, volleyball is also an important team sport and it has an increasing popularity in the recent period, however, pupils do not tend to participate in the physical education lessons for this game. The researcher thinks the main reason for this phenomenon is using a typical method of teaching, which is the traditional method (giving orders) in teaching the lessons of volleyball skills (high pass). Previous studies showed that active learning is one of the modern teaching methods used recently, therefor the researcher used the active learning (exchange learning and collaborative learning strategies) to teach the high pass in volleyball to stimulate the learners to participate actively in learning and teaching processes themselves the two active learning strategies (exchange learning and self-learning strategies) which help raising the level of their performance of the high passing skill as the active learning is a modern method of teaching, which encourages the learner to actively participate in the educational process.

Active learning is based on some basic elements which are: (students' involvement in choosing the work system and its rules - Using the teaching strategies that focus on the learner, which commensurate with their abilities and interests, learning patterns and intelligences - Selfevaluation and evaluating the colleagues - Permitting the students to self-management - The level of learning of each student regarding his/her abilities and own pace, and his/her advantages in (encouraging the learners to be involved more in work to make learning interesting and joyful - enhancing self-confidence and the ability to express opinions - increasing the desire to learn until being master - enabling the students to get used to the work rules, and develop their tendencies and positive values - help finding positive interactions among students - promoting positive competition among the students. $(2: 44,45)$

- Active Learning Strategies: include (dialogue and debate strategy - brainstorming strategy - problem-solving strategy - exploration strategy - collaborative learning strategy - peer-learning strategy - self-learning strategy academic games strategy - playing roles strategy concept mapping strategy. $(2: 49,52)$

The researcher will use in this research both (peer-learning (exchange) strategy - cooperative learning strategy)

\section{- Peer learning strategy:}

Said El-Shahed (1995) points that collaborative learning style allows the students to be more free and independent to educate themselves, compared to other styles, this type of learning helps reducing the problem of large numbers of students in institutes and schools, and it helps the teacher to follow up all students at the same time, also it enables making use of a colleague's help in the following formats (observer - assistant - associate - competitor). (10:74-77)

Mohsen Mohamed Homos (1997) also says that this style depends on the feedback provided by the colleague, in order to correct the path of motor performance to reach the desired goal of the practice. (12:94).

\section{- Collaborative learning strategy:}

Mohamed El-Deeb (2007) explained that there are many forms for collaborative learning which concern with the pupil's enthusiasm in the educational process and his/her positive participation and concentration on the importance of the interaction between the students and the educational material. The students must recognize, during the educational situations, that they are part of the whole working group, so they become able to achieve their common goals, realize any problem that may face them and try to solve it together. They all have to believe that both success and failure depend on their team work. (18:1, 2)

Hassan Zaytoun (2006) declared that collaborative learning is a type of classroom learning in which the students are divided into small collaborative groups. This 
type of learning sets a basis to develop both the academic achievement and social skills together, the collaborative group consists of 2-6 members, who are usually heterogenous. All members of each group participate together on their mission through direct interaction, exchanging experiences and providing researches and feedback. They may distribute the tasks so each one can finish his own part and then share their experiences. This process would increase individual's awareness that he is not only responsible for his success in learning the task, but also responsible for the success of the entire group. (8:246-247)

\section{High passing skill:}

Ali Taha (2002) showed that the passing skill is to direct the ball by hands and change its direction while the ball keeps moving, this is considered the most important and skill as well as the most used one in volleyball, the team is not successful unless the players have the ability to control the direction of the ball in all directions correctly and legally. This skill is important also for defense and attack plans used by the team.

He explains the technical points of the high passing skill to the front: a simplified explanation of the importance of the high pass skill (setting), due to its important role in the success of smash hits where "the ball is being passed by the fingers only - the right posture regarding the palm of the hand in front of the face with extended legs, trunk and arms to follow the passing process - controlling the body at the end of movement. (11:76)

The main types of high passing according to Akram Khattabiya (1996), high passing (forward - backward - to both sides - jumping - rolling - after rotation - with falling - from pike posture. $(1: 102)$

\section{Aims of the study:}

This study aims to recognizing the effect of using active learning with two strategies (peer learning and collaborative learning) on the performance level of high pass in volleyball for the first preparatory grade pupils.

\section{Hypotheses:}

1. There are statistically significant differences between the pre- and post-measurements in the tests of performance level of high pass skill in volleyball among the experimental group pupils in favor to the postmeasurement.

2. There are statistically significant differences between the pre- and post-measurements in the tests of performance level of high pass skill in volleyball among the control group pupils in favor to the pre-measurement.

3. There are statistically significant differences between the two post-measurements in the tests of performance level of high pass skill in volleyball among the pupils of the experimental and the control groups in favor to the experimental group.

Some previous studies concerned with active learning strategies in the educational process, one of which is ElMahdy Mahmoud Salem's study (2001) (3). The results showed that using active learning strategy has increased the achievement level and understanding of concepts and formation of positive trends about learning physics. Further more, the results of Amany El-Sayed's study (2009) (4) proved that using active learning has a positive effect in raising educational achievement as well as enhancing creative thinking. While Mohammed Hammad Hendy's study (2002) (14) of using active learning strategies encouraged the students towards interdependence in the acquisition of certain biological concepts. Heba El-Shebokshy's study (2007) (20) concluded that the teaching strategy of active learning has a positive effect on the cooperative attitudes among students and the acquisition of scientific concepts. In the meantime, the study of Walid El-Demerdash Omara (2004) (21) showed the experimental group's supremacy which learned using self-learning style in concept of skillful-self and the performance level of release in volleyball. Finally the results of Tandogan's study (2007) (22) revealed that the use of active learning based on problem solving has increased the conceptual growth for the students who used this strategy.

\section{Study Procedures:}

Method: Experimental with pre- post-measurements to two groups (experimental - control)

Study Sample: The study was applied to a sample consisted of (40) pupils of the first preparatory grade of Atlamis Preparatory School at Delengat County in Beheira Governorate. They were randomly chosen and divided into two groups, of which the first is experimental consisted of (20) pupils, active learning was applied on them (collaborative learning strategy and peer-learning strategy), while the other group experienced the traditional style "giving orders" which is used in teaching the high passing skill forward in volleyball. This group also consisted of (20) pupils. Tables (4) (5) (6) (7) and Attachment (1) show the homogeneity of the sample's individuals and the equivalence achievement between the two groups in the primary research variables (age - length 
- weight) and physical abilities and skillful tests of high passing skill forward in volleyball.

\section{Study tools:}

I) the physical abilities tests:

Physical abilities tests were used as cited by the references (23) (2000), (22) (2001). Scientific transactions were conducted for these tests to ensure the reliability and validity of these tests on a sample of 10 students from outside the research sample, as shown in Tables (8) (9) and Attachment (2).

II) Assessing the performance level of the high passing skill forward in volleyball was done in two methods of which the first is: the skill test (class) to the high passing skill forward in volleyball. Attachment (3)

The second method: (Application of monitoring performance) to the high passing skill forward in volleyball. The researcher designed an application and presented it to the experts. Attachment (4)

Validity of the application of monitoring was calculated by the arbitrators, they all have accepted it, while reliability of the application was set to be 0.83 .

Setting the active learning program for the experimental group
- The module (high passing skill forward in volleyball) was designed for the experimental group by active learning strategies (collaborative learning and peerlearning strategies) as follows:

- High passing skill forward in volleyball was taught by both (collaborative learning and peer-learning strategies) in papers that include the main parts of the lesson sheets (educational and practical parts).

The content of the module was identified and distributed to (4) lessons during the main experiment of the research for (4) weeks, each week include two lessons.

Time taken for each lesson is (90 minutes) where the main part took (50 minutes) which is the time for the experimental variable of active learning (collaborative learning and peer-learning strategies) and the traditional method (giving orders). The program of active learning was presented to the experts and specialists in curricula, teaching methods and volleyball, Attachment (5). The researcher also took into consideration the factors of experimental adjustment between the two groups.

- The main experience was conducted from 13/10/2013 to $7 / 11 / 2013$, while the pilot study was made on a sample consisted of (10) students from outside the sample from $1 / 10 / 2013 \mathrm{~m}$ to $10 / 10 / 2013$.

\section{Results:}

Table (1)

Significant differences between pre- and post-measurements to the experimental group in the performance level tests of high passing skill forward in volleyball to the first preparatory grade pupils $(n=20)$

\begin{tabular}{|c|c|c|c|c|c|c|c|}
\hline \multirow[b]{2}{*}{ Tests } & \multicolumn{2}{|c|}{ Post measurement } & \multicolumn{2}{|c|}{ Pre measurement } & \multirow{2}{*}{$\begin{array}{c}\text { Differenc } \\
\text { es } \\
\text { between } \\
\text { means }\end{array}$} & \multirow[b]{2}{*}{ (t) value } & \multirow{2}{*}{$\begin{array}{c}\text { Enhanceme } \\
\text { nt } \\
\text { percentage }\end{array}$} \\
\hline & $\begin{array}{l}\text { Arithmeti } \\
\text { c mean }\end{array}$ & $\begin{array}{l}\text { Standard } \\
\text { deviation }\end{array}$ & $\begin{array}{l}\text { Arithmeti } \\
\text { c mean }\end{array}$ & $\begin{array}{l}\text { Standard } \\
\text { deviation }\end{array}$ & & & \\
\hline $\begin{array}{l}\text { High pass } \\
\text { "60 degrees" }\end{array}$ & 37.50 & 7.75 & 27.30 & 4.68 & 9.20 & 4.547 & $32.70 *$ \\
\hline $\begin{array}{l}\text { Assessing the performance level of } \\
\text { high passing skill "degree" }\end{array}$ & 7.45 & 2.27 & 4.12 & 1.12 & 3.33 & 5.889 & $31.41 *$ \\
\hline
\end{tabular}

(t) value was at the level of $0.05=2.09^{*}, 0.01=2.89 * *$

Table (1) shows that there are statistically significant differences at the level of 0.05 between the post and premeasurements in the performance level tests of high passing skill forward in volleyball for the 10 first preparatory grade pupils (experimental group) in favor to the post-measurement. 
Table (2)

Significant differences between pre- and post-measurements to the control group in the performance level tests of high passing skill forward in volleyball to the first preparatory grade pupils $(n=20)$

\begin{tabular}{|c|c|c|c|c|c|c|c|}
\hline \multirow{2}{*}{ Tests } & Statistical processors & \multicolumn{2}{|c|}{ Post measurement } & \multicolumn{2}{|c|}{ Pre measurement } & $\begin{array}{c}\text { Differenc } \\
\text { es } \\
\text { between } \\
\text { means }\end{array}$ & $\begin{array}{c}\text { Enhanceme } \\
\text { (t) value } \\
\text { percentage }\end{array}$ \\
\hline $\begin{array}{c}\text { High pass } \\
\text { "60 degrees" }\end{array}$ & 30.10 & 3.412 & 25.20 & 2.460 & 4.90 & $5.207^{* *}$ & $29.57^{*}$ \\
\hline $\begin{array}{c}\text { Assessing the performance level of } \\
\text { high passing skill "degree" }\end{array}$ & 5.24 & 2.32 & 3.67 & 1.34 & 1.57 & $3.048^{*}$ & $17.25^{*}$ \\
\hline
\end{tabular}

(t) value was at the level of $0.05=2.09 *, 0.01=2.89 * *$

Table (2) shows that there are statistically significant differences at the level of 0.01 between the post and premeasurements in the performance level tests of high passing skill forward in volleyball for the first preparatory grade pupils (control group) in favor to the postmeasurement.

Table (3)

Significant differences between the two post-measurements to the experimental and control groups in the performance level tests of high passing skill forward in volleyball to the first preparatory grade pupils

\begin{tabular}{|c|c|c|c|c|c|c|c|c|}
\hline \multirow{2}{*}{ Tests } & \multicolumn{2}{|c|}{ Experimental group } & \multicolumn{2}{|c|}{ Control group } & \multirow{2}{*}{$\begin{array}{l}\text { Differe } \\
\text { nces } \\
\text { between } \\
\text { means }\end{array}$} & \multirow{2}{*}{$\begin{array}{c}\text { Standard } \\
\text { deviation of } \\
\text { the } \\
\text { differences }\end{array}$} & \multirow{2}{*}{$\begin{array}{c}(\mathrm{t}) \\
\text { value }\end{array}$} & \multirow{2}{*}{$\begin{array}{c}\text { Enhanceme } \\
\text { nt } \\
\text { percentage }\end{array}$} \\
\hline & $\begin{array}{l}\text { Arithmet } \\
\text { ic mean }\end{array}$ & $\begin{array}{l}\text { Standard } \\
\text { deviation }\end{array}$ & $\begin{array}{l}\text { Arithmetic } \\
\text { mean }\end{array}$ & $\begin{array}{l}\text { Standard } \\
\text { deviation }\end{array}$ & & & & \\
\hline $\begin{array}{l}\text { High pass } \\
\text { "60 degrees" }\end{array}$ & 37.50 & 7.75 & 30.10 & 3.412 & 7.40 & 8.35 & $3.909 * *$ & 23.45 \\
\hline $\begin{array}{l}\text { Assessing the } \\
\text { performance level of high } \\
\text { passing skill "degree" }\end{array}$ & 7.45 & 2.27 & 5.24 & 2.32 & 2.21 & 4.55 & $3.67 * *$ & 19.24 \\
\hline
\end{tabular}

(t) value was at the level of $0.05=2.09^{*}, 0.01=2.89 * *$

Table (3) shows that there are statistically significant differences between the experimental group and the control group in the post-measurements of the performance level tests of high passing skill forward in volleyball for the first preparatory grade pupils in favor to the experimental group.

\section{Discussion:}

Table (1) showed that there are statistically significant differences between the pre- and post-measurements of the experimental group in the performance level tests of high passing skill forward in volleyball for the first preparatory grade pupils where the calculated $(\mathrm{t})$ value ranged between (4.547-5.889), and that was greater than the tabulated $(\mathrm{t})$ value (2.09-2.89) at the level of $0.05,0.01$. The researcher explains the reasons for the differences as a result of using two types of active learning strategies (collaborative learning and peer-learning strategies) which is the primary means to the great positive effect on the performance level of high passing skill forward in volleyball, as it depends on the active participation of the learner, in addition to having him/her involved in the educational process, when the teacher assigns his/her pupils to specific tasks within the group, at this moment they apply either collaborative learning or peer-learning to achieve the required target. At last the work of all individuals within the group is merged to achieve the main goal which is learning how to perform the high passing skill forward in volleyball and this is consistent with Heba El-Shebokshy's (2007) (20) opinion that teaching with an active learning strategy has a positive effect on cooperative attitudes among students and the acquisition of scientific concepts and thus raising the level of their performance in high passing skill in volleyball. So the first hypothesis is achieved.

As shown in Table (2), there are statistically significant differences between the pre- and post-measurements in favor to the post-measurement of the control group in performance level tests of the high passing skill forward in volleyball for the first preparatory grade pupils, where the calculated $(\mathrm{t})$ value ranged between $(5.270 * *-3.048 *)$ which is greater than the tabulated $(\mathrm{t})$ value $(2.09,2.89)$ at the level of $0.05,0.01$. The researcher indicates that the difference occurred as a result of using traditional method (giving orders), which depends on the teacher in all phases, the teacher here is responsible for planning, implementation, and evaluation, and his/her role is to 
negatively obey orders and do what he/she asked for. So the second hypothesis is true.

The results of Table (3) showed that there are statistically significant differences between the post-measurements of the experimental and control groups in the performance level tests of high passing skill forward in volleyball for the first preparatory grade pupils in favor to the experimental group where the calculated $(\mathrm{t})$ value ranged between $(3.909 *-3.670 *)$ which is greater than the tabulated $(\mathrm{t})$ value $(2.09,2.89)$ at a level of $0.05,0.01$, and the rate of improvement was high because the value ranged from (23.45-19.24). The researcher proved that the positive effect of using active learning with both strategies (collaborative learning and peer-learning), which lead to the great positive effect on the performance level of the high passing skill forward in volleyball because it depends on the active participation of the learner during the educational process and interdependence of the students of the same group (triple or double) to achieve unified and specific targets, and that agrees with Mohammed Hammad Hendy's study (2002) (14).

\section{Conclusions:}

In light of the findings of the results we can conclude the following:

1. Using active learning with collaborative learning and peer-learning strategies had a positive effectiveness on learning the high passing skill forward in volleyball, which led to raising the performance level of the first preparatory grade pupils of Atlamis School in Beheira Governorate in the experimental group.

2. Using the style of giving commands "traditional style" had an obvious effect on learning the high passing skill forward in volleyball, which led to raising the performance level of the first preparatory grade pupils of Atlamis School in Beheira Governorate in the control group.

3. Active learning with both (collaborative learning and peer-learning strategies) for the pupils in the experimental group was more effective than the traditional style with giving commands in the control group on learning the high passing skill forward in volleyball, and their performance level of this skill.

\section{Recommendations:}

After reviewing the findings, the researcher recommends the following:
1. Using active learning with (collaborative learning and peer-learning strategies) in teaching the high passing skill forward in volleyball, as it has proved its effectiveness.

2. Using active learning with (collaborative learning and peer-learning strategies) in teaching the rest of volleyball skills, as it has proved its effectiveness in teaching the high passing skill forward.

3. Carrying out further research and studies for the rest of offensive and defensive volleyball skills.

4. Using different strategies for active learning in various motor skills of various activities.

\section{References:}

1. Akram Khattabiya (1996): Encyclopedia of Modern Volleyball, Dar Al-Fikr, Amman, Jordan, 1996.

2. National Center for Educational Research and Development (2006): Evaluating the Active Learning Experience in the Elementary School in the Arab Republic of Egypt, Cairo.

3. El-Mahdy Mahmoud Salem (2006): The Effect of Active Learning Strategies on Achievement, Conceptual Understanding and Trends towards Learning Physics for the First Secondary Grade Students; Scientific Education Journal, Vol. IV - No. 2 - (June), Faculty of Education, Ain Shams University, Cairo.

4. Amany El-Sayed Farghaly Selim (2009): The Effect of Active Learning in Development of Creative Thinking and Studying Achievement for the First Grade Pupils of Basic Education, Unpublished Master Thesis, the Institute of Educational Studies, Cairo University.

5. Amin Anwar El-Khouly, Gamal-Eddin El-Shafey (2000): Contemporary Physical Education Curricula, Dar Al-Fikr Al-Araby, Cairo.

6. Amin Farooq Fahmy (2001): Systematic Trend in Teaching and Learning, First Arab Conference on Systematic Trend in Teaching and Learning, Development of Teaching Sciences Center, Regional Office of UNESCO in Cairo, Ain Shams University, 17-18 February.

7. Borhamy Abdel-Hamid Zaghloul (2012): Teaching Commercial Sciences, Manual of Quality for Teaching and Learning, El-Nahda El-Masriya Library, Cairo.

8. Hassan Hussein Zaytoun (2006): Teaching Strategies, Contemporary Vision for Teaching and Learning Methods, First Edition, Alam Al-Kotob, Cairo. 
9. Active Learning Guide (2006): Development of Curricula and Educational Materials Center, the Ministry of Education, the Arab Republic of Egypt.

10. Said Khalil El-Shahed (1995): Teaching Methods in Physical Education, Students Library, Shoubra, Cairo.

11. Aly Moustafa Taha (2002): Creating a Knowledge Test in Volleyball for the Students of the Faculty of Physical Education (Education Division), The Scientific Journal, Volume V, (December), Faculty of Physical Education, University of Suez Canal, Port Said.

12. Mohsen Mohamed Homos (1996): The Guide of Teaching Physical Education, Mansha'at Al-Maaref, Alexandria.

13. Mohamed Al-Hamahemy, Amin Anwar El-Khouly (1990): Basics of Making Physical Education Programs, Dar Al-Fikr Al-Araby, Cairo.

14. Mohamed Hammad Hendy (2002): The Impact of the Diversity of Using Certain Active Learning Strategies to Gain Some Biological Concepts and Self-Esteem, Trending toward Interdependence among the Agricultural First Secondary Grade Students, Studies in Curricula and Teaching Methods, No. 79, April, Faculty of Education, Ain Shams University, Cairo.

15. Mohamed Hassan Allawy, Mohamed Nasr-Eddin Radwan (2001): Tests of Motor Performance, Dar Al-Fikr Al-Araby, Cairo.

16. Mohamed Ziad Hamdan (2006): Indicators of Active Learning in the Twenty First Century, Curricula and
Teaching Methods Department, Faculty of Education, Zagazig University.

17. Mohamed Sobhy Hassanein (2000): Measurement and Evaluation in Physical Education and Sports, Part II, Fourth Edition, Dar Al-Fikr Al-Araby, Cairo.

18. Mohamed Mustafa El-Deeb (2007): Contemporary Strategies in Collaborative Learning, Alam Al-Kotob, Cairo.

19. Makarem Hilmy Abu-Harjah, Mohamed Saad Zaghloul (1999): Physical Education Curricula, Book Center for Publishing, Cairo.

20. Heba Galal El-Sayed El-Shebokshy (2007): The Effect of Using Active Learning Strategies to Acquire Scientific Concepts in Science Subject and Development of Cooperative Attitudes among Preparatory School Pupils, Unpublished Master Thesis, Faculty of Education, Zagazig University.

21. Walid El-Demerdash Omara (2004): The Effect of Exploring and Self-Learning Styles on the Concept of Skillful-Self and the Performance Level of Transmission in Volleyball for the Preparatory Grade Students, Unpublished Master Thesis, Faculty of Physical Education, Mansoura University.

22. Tandogan, R., Akinoglu, O: (2007): The Effects of Problem Based Active Learning in Science Education on Students Academic Achievement, Attitude and Concept Learning On Line Submission, Eurasia Journal of Mathematics, Science and Technology Education, Vol. 3, No. 1, PP.77-81, Eric.no: Ej752356. 